\title{
Chlorophyll Fluorescence as a Nondestructive Indicator of Freshness in Harvested Broccoli
}

\author{
Peter M.A. Toivonen \\ Agriculture Canada, Research Station, Agassiz, B.C. VOM 1A0, Canada \\ Additional index words. Brassica oleracea (Botrytis group), quality, chlorophyll, \\ ascorbic acid, respiration rate
}

\begin{abstract}
Chlorophyll "a" fluorescence (Fvar) was compared with respiration and vitamin C content of broccoli [Brassica oleracea $\mathbf{L}$. (Botrytis group)] during storage at 1C. The amplitude of the Fvar maxima declined in a similar manner as respiration and vitamin $C$ content. Fvar was highly correlated with respiration $(r=0.83, P>|r|$ $=0.0001)$. The correlation of Fvar with vitamin $C$ content was weaker $(r=0.42$, $P>|\mathbf{r}|=0.0002)$. The results demonstrate that $\mathrm{Fvar}$ is an indicator of postharvest changes in broccoli and that Fvar can be used as a nondestructive indicator of early changes in tissue condition (i.e., degree of freshness) of broccoli in storage.
\end{abstract}

Rapid, nondestructive methods are needed to assess changes in quality of vegetables (Watada, 1989). An important component of quality in many cases is the degree of freshness. Loss of freshness may not itself reflect large measurable changes in quality, but it precedes visible and readily measurable tissue deterioration. Any deterioration or decline of tissue from a freshly harvested state is considered a decline in freshness (Schwerdtfeger, 1979). Early changes of various tissue characteristics in vegetables have been identified, including respiration, free amino acids, vitamin $\mathrm{C}$, and chlorophyll content (Perrin and Gaye, 1986; Schwerdtfeger, 1979; Solomos, 1983; Thimann, 1987). These changes are closely correlated, and they occur either in parallel or sequentially as the tissue begins to subsequently senesce (Thimann, 1987). Measurement of these characteristics involves a considerable amount of time to either process samples and/or perform analyses.

Received for publication 13 June 1991. Accepted for publication $23 \mathrm{Apr}$. 1992. The cost of publishing this paper was defrayed in part by the payment of page charges. Under postal regulations, this paper therefore must be hereby marked $a d$ vertisement solely to indicate this fact.
Two methods involving measurements of chloroplast function have been used for assessment of health of plant tissue. Delayed light emission (DLE) and chlorophyll "a" fluorescence (Fvar) are sensitive to changes at the cellular level; however, chlorophyll fluoresecence generally has been found to be more useful (Havaux and Lannoye, 1985). DLE transients consist of many components and are affected by temperature, whereas Fvar analysis is relatively insensitive to temperature and the interpretation of transients is simpler (Jursinic, 1986; Krause and Weis, 1984). Fvar has been used to monitor ripening and chilling injury in tropical fruits (Smillie et al., 1987) and determine poststorage viability of conifer seedlings (Vidaver et al., 1989). Compared with DLE, the fluorescence assessment is simple to use, portable, and relatively inexpensive. Measurement of a single sample can take as little as 10 set, and data interpretation can be done almost immediately.

This work was done to determine if chlorophyll fluorescence changes could be used to assess changes in tissue condition of broccoli, as has been done with established methods such as respiration measurement and vitamin $\mathrm{C}$ analysis. Changes in respiration rate and vitamin $\mathrm{C}$ content are considered sensitive indicators of changes in tissue condition after harvest (Perrin and Gaye, 1986; Solomos, 1983).

Broccoli used in this study was grown at the Agriculture Canada Research Station, Agassiz, B.C.; it was harvested on 28 Sept. 1990 and placed into storage at $1 C$, relative humidity $97 \% \pm 2 \%$. During the course of storage, samples were taken for fluorescence, respiration, and vitamin $\mathrm{C}$ analysis.

The experiment was a randomized complete-block design. In all experiments, 24 replicates were selected at each of three times during storage. Three heads per replicate were subsampled for fluorescence and respiration measurement. For the latter, these three subsamples were bulked into one respiration chamber, and for Fvar measurement, three samples were averaged into one value. Only one head was sampled for each replicate in the vitamin $\mathrm{C}$ analysis.

Samples were placed into a dark room for 15 min, before the Fvar measurement, which was performed with a model SF30 Plant Productivity Fluorometer (Richard Brancker Res., Ottawa). The excitation light level was set at $650 \mathrm{~W} \cdot \mathrm{m}^{-2}$ and measurement was for 10 sec. Stray light was corrected for by use of a color standard that approximated the reflectance of the broccoli. Fvar was expressed as maximum aplitude of the variable component relative to the nonvariable component of chlorophyll "a" fluorescence (Toivonen and Vidaver, 1988).

Respiration measurements were performed at 4C. Samples were placed in 12liter polyethylene pails with tight-fitting lids. The pails were sealed and flushed with gas free of $\mathrm{CO}_{2}$, and at time zero a measurement was taken. A subsequent sample was taken $\approx 1 \mathrm{~h}$ later by flushing a gas sample bulb with sample atmosphere. The $\mathrm{CO}_{2}$ was determined on a Shimadzu GC-9A gas chromatograph (TekScience, Oakville, Ont.), fitted with a $8 \times 0.0032 \mathrm{~m}$ Porapak Q (Supelco, Oakville, Ont., 80/100 mesh) column. The oven temperature was $75 \mathrm{C}$ and the helium carrier flow set at $50 \mathrm{ml} \cdot \mathrm{min}^{-1}$. A methanizer (at 350C) converted the $\mathrm{CO}_{2}$ to methane, which was then measured by an FID detector (at 250C).

Vitamin $\mathrm{C}$ analyses were performed on tissue samples, including floral portions and stem tissue, that are normally considered to 


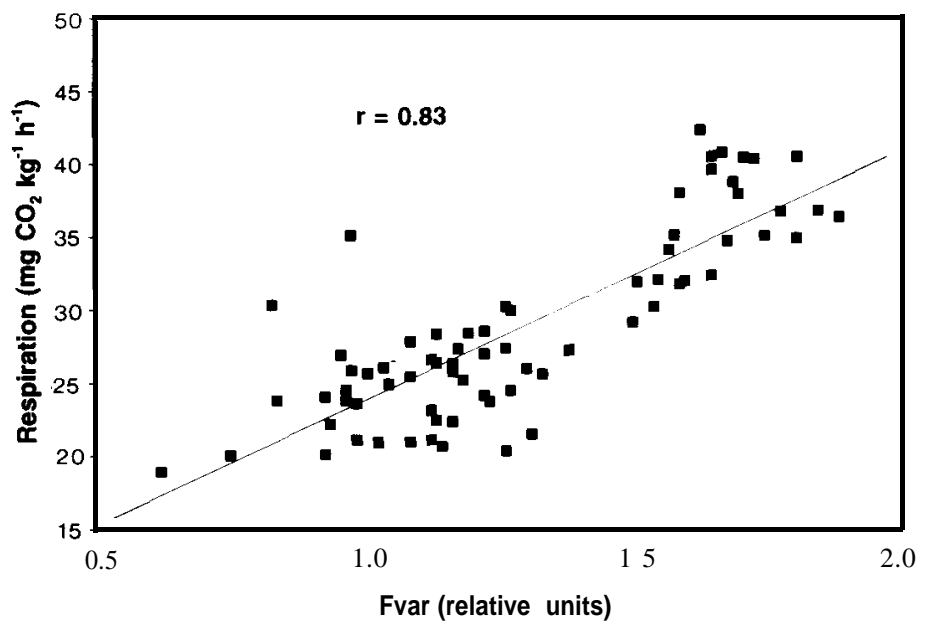

Fig. 1. Correlation of respiration and relative fluorescence (Fvar) of broccoli kept for 24 days at $1 \mathrm{C}$ and $97 \% \pm 2 \%$ relative humidity. The equation of the fitted line is $y=16.80 \times+7.27$.

Table 1. Changes in respiration, vitamin $\mathrm{C}$ content, and maximum Fvar amplitude of broccoli kept at $1 \mathrm{C}$ and $97 \% \pm 2 \%$ relative humidity.

\begin{tabular}{lccc}
\hline \hline $\begin{array}{l}\text { Time in storage } \\
\text { (days) }\end{array}$ & $\begin{array}{c}\text { Respiration rate } \\
\left(\mathrm{mg} \mathrm{CO}_{2} / \mathrm{kg} \text { per } \mathrm{h}\right)\end{array}$ & $\begin{array}{c}\text { Vitamin } \\
(\mathrm{mg} / 100 \mathrm{~g} \text { fresh wt })\end{array}$ & $\begin{array}{c}\text { Fvar } \\
\text { (relative units) }\end{array}$ \\
\hline 4 & $36.6^{2}$ & 81.8 & 1.67 \\
12 & 26.5 & 73.8 & 1.20 \\
$20-24$ & 23.6 & 73.0 & 0.98 \\
Significance & $* * *$ & $* *$ & $* * *$ \\
$\quad$ Linear & $* * *$ & $\mathrm{NS}$ & $* * *$ \\
\hline
\end{tabular}

${ }^{2}$ Average of 24 replicates.

${ }^{* * \mathrm{NS}_{\mathrm{S}}}$ Significant at $P=0.01$ or 0.001 or not significant, respectively.

be the edible portion. A 5-g sample was homogenized in $50 \mathrm{ml}$ of $0.4 \%$ oxalic acid (Perrin and Gaye, 1986). After centrifuging, the aqueous supernatant was partitioned against chloroform, then diethyl ether, and filtered. Twenty microliters of the resultant aqueous phase was analyzed with a Beckman gradient liquid chromatograph (Model 322), using a $250 \times 4.6 \mathrm{~mm}$ Beckman Ultrasphere-ODS column (Beckman Instruments, Toronto). The mobile phase was $2 \%$ aqueous $\mathrm{N} \mathrm{H}_{4} \mathrm{H}_{2} \mathrm{PO}_{4}(\mathrm{pH}$ 2.8). Vitamin $\mathrm{C}$ was detected at $245 \mathrm{~nm}$.

There was a significant decline in the Fvar over the period of the experiment (Table 1). The decline in Fvar represents a general decline in chloroplast function (Krause and Weis, 1984). There was no visually apparent chlorosis or yellowing of the samples during this experiment. Weight loss was $5.5 \%$ by day 12 and $9.5 \%$ by the end of the experiment. Some signs of wilting were apparent only at the end of the experiment. The changes in Fvar reflect early stages of chloroplast deterioration, presumably associated with water loss, and not senescence, hence reflecting a decline in freshness.

Respiration rate and vitamin $\mathrm{C}$ concentration also declined significantly during storage (Table 1). Respiration was highly correlated with Fvar $(r=0.83, P$ 犺 $\mid=$ 0.0001) (Fig. 1). While the correlation be- tween vitamin $\mathrm{C}$ content and Fvar was significant $(P>|\mathrm{r}|=0.0002)$, the relationship was rather weak $(r=0.42)$. After an initial decline from day 4 to 12 , the vitamin $\mathrm{C}$ content did not change appreciably, while respiration and Fvar continued to decline (Table 1). The plot of respiration against Fvar and their correlation is shown in Fig. 1.

Measurements of respiration and Fvar provide direct information on the functioning of the mitochondria and chloroplast, respectively. These organelles are very sensitive to early stages of deterioration in plant tissue (Dalling and Nettleton, 1986; Solomos, 1983). While vitamin $C$ is very labile (Perrin and Gaye, 1986), its tissue content is determined by the complements of other components of an oxidant protective system and the rate of production of active oxygen species by the mitochondria and chloroplast (Salin, 1987). Thus, the vitamin C content is determined by a complex biochemical matrix and the state of mitochondrial and chloroplast function; therefore, it may not completely reflect changes in either organelle's function. The relatively weak correlations of vitamin $\mathrm{C}$ with respiration ( $r=$ 0.37) and Fvar ( $r=0.42)$ bears out this reasoning.

The results show that Fvar analysis can be used to obtain freshness assessments similar to those provided by measurement of respi- ration. Vitamin $\mathrm{C}$ provided parallel information during the early period of storage. Fvar is the least expensive and time-consuming of the three methods. It was capable of monitoring early stages of deterioration in a green vegetable because it produced information that was consistent with another established method. The method is also practical for many samples, since each measurement takes $\approx 10 \mathrm{sec}$ to complete. Hence, Fvar has great potential as a nondestructive method for assessing decline in freshness of green vegetables, such as broccoli, during cold storage.

\section{Literature Cited}

Dalling, M.J. and A.M. Nettleton, 1986. Chloroplast senescence and proteolytic enzymes, $\mathrm{p}$. 125-153. In: M.J. Dalling (ed.). Plant proteolytic enzymes vol. II. CRC, Boca Raton, Fla.

Havaux, M. and R. Lannoye. 1985. In vivo chlorophyll fluorescence and delayed light emission as rapid screening techniques for stress tolerance in crop plants. Z. Pflanzenzichtg. 95:113.

Jursinic, P.A. 1986. Delayed fluorescence: Current concepts and status, p. 291-329. In: J. Amesz Govindjee and D.C. Fork (eds.). Light emission by plants and bacteria. Academic, Orlando, Fla.

Krause, G.H. and E. Weis. 1984. Chlorophyll fluorescence as a tool in plant physiology. II. Interpretation of fluorescence signals. Photosynthesis Res. 5:139-157.

Perrin, P.W. and M.M. Gaye. 1986. Effects of simulated retail display and overnight storage treatments on quality maintenance in fresh broccoli. J. Food Sci. 51:146-149.

Salin, M.L. 1987. Toxic oxygen species and protective systems of the chloroplast. Physiol. Plant. 72:681-689.

Schwerdtfeger, E. 1979. Freshness as a part of vegetable quality. Acta Hort. 93:35-44.

Smillie, R.M., SE. Hetherington, R. Nott, G.R. Chaplin, and N.L. Wade. 1987. Applications of chlorophyll fluorescence to the postharvest physiology and storage of mango and banana fruit and the chilling tolerance of mango cultivars. Asean Food J. 3:55-59.

Solomos, T. 1983. Respiration and energy metabolism in senescing plant tissues, p. 61-98. In: M. Lieberman (ed.). Post-harvest physiology and crop preservation. Plenum, New York.

Thimann, K.V. 1987. Plant senescence: A proposed integration of the constituent processes, p. 1-19. In: W.W. Thomson, E.A. Nothnagel, and R.C. Huffacker (eds.). Plant senescence: Its biochemistry and physiology. Amer. Soc. Plant Physiol., Rockville, Md.

Toivonen, P. and W. Vidaver. 1988. Variable chlorophyll a fluorescence and $\mathrm{CO}_{2}$ uptake in water-stressed white spruce seedlings. Plant Physiol. 86:744-748.

Vidaver, W., W. Binder, R.C. Brooke, G.R. Lister, and P.M.A. Toivonen. 1989. Assessment of photosynthetic activity of nursery-grown Picea glauca seedlings using an integrating fluorometer to monitor variable chlorophyll fluorescence. Can. J. For. Res. 19:1478-1482.

Watada, A.E. 1989. Nondestructive methods of evaluating quality of fresh fruits and vegetables. Acta Hort. 258:321-329. 